\title{
Produtos e serviços da web 2.0 no setor de referência das bibliotecas
}

Deise Lourenço de Jesus

\author{
Bibliotecária e Consultora independente
}

Murilo Bastos da Cunha

\begin{abstract}
Professor da Faculdade de Ciência da Informação da Universidade de Brasília
\end{abstract}

Este trabalho busca demonstrar como as ferramentas da web 2.0 podem atuar nas bibliotecas, auxiliando o processo de atendimento ao usuário e promovendo melhorias nos serviços prestados pelo setor de referência. São apresentadas as principais ferramentas e suas funcionalidades, identifica exemplos da sua utilização em unidades de informação, introduz aspectos sobre 0 surgimento da internet e da web 2.0. Focaliza o atendimento ao usuário e compara as gerações de bibliotecas (biblioteca 1.0 x biblioteca 2.0). A partir de então, são apresentados exemplos de como tais ferramentas podem ser utilizadas no setor de referência. Conclui, apontando a importância da adoção dessas ferramentas em bibliotecas e indicando que a utilidade das mesmas é um fato que deve ser considerado pelos profissionais brasileiros, como ponto central do processo de evolução das bibliotecas.

Palavras-chave: Internet; Serviço de Referência; Web 2.0.

\section{Products and services of web 2.0 in the reference sector of libraries}

This paper aims at demonstrating how web 2.0 tools can operate in libraries helping the user's care process and promoting improvements in the services of the reference sector. The main tools and features are identified, examples of their application in libraries are commented, and aspects about the appearance of the internet and web 
2.0 are introduced. This study also focuses on costumers' service and compares the generation of libraries ( $1.0 \mathrm{X}$ 2.0 ). Examples of how to use these tools in the reference sector are presented. It is concluded that the adoption of these tools in libraries is very important and is a fact that should be considered by Brazilian information professionals as main point of the evolution process of libraries.

Keywords: Internet; Reference Service; Web 2.0.

Recebido em 24.08.2010 Aceito 25.01.2012

\section{Introdução}

O mundo globalizado permitiu o avanço da tecnologia de maneira surpreendente e poucos conseguem acompanhar tais inovações. Um dos papéis da nova biblioteca ou, como alguns autores já denominaram, a "biblioteca 2.0", é se utilizar de toda essa tecnologia disponível, para melhorar e aperfeiçoar os seus produtos e serviços. A web 2.0 disponibiliza recursos de interação e compartilhamento que podem auxiliar no processo de desenvolvimento de setores importantes da biblioteca, como o setor de referência.

A biblioteca tradicional, como instituição que todos estão acostumados a imaginar, está sofrendo enormes mudanças. A partir dos anos 1980, os sistemas para informatização das bibliotecas passaram a estar disponíveis em um nível avançado de desenvolvimento, com todos os setores interligados, ou seja, um mesmo sistema cadastra usuário, realiza empréstimos e devoluções, além de fazer todo o processamento técnico do livro, da catalogação à impressão de etiquetas. Inicialmente, esses sistemas utilizavam grandes computadores (os denominados mainframes) para processarem essa massa de dados e, paulatinamente, migraram para equipamentos menores. Além disto, somente sistemas proprietários eram comercializados; hoje, existem inúmeros programas de acesso livre, que facilitaram, sobremaneira, a automação.

O foco das bibliotecas está se voltando para as tecnologias que podem se aliar ao funcionamento interno e externo dessas unidades. Os usuários e como a informação será repassada para eles, é um dos pontoschave desse desenvolvimento. Dessa maneira, é necessário um estudo de como essas tecnologias que surgem na web podem se tornar aliadas no processo de atendimento do usuário. Ferramentas como o YouTube, Wiki, sítios de relacionamento, como o Facebook e o MySpace, são exemplos de como a biblioteca pode se inteirar dessa tecnologia, utilizando o conteúdo disponibilizado para auxiliar o atendimento ao usuário. A web 2.0 também pode estar presente de outras maneiras, como na divulgação da biblioteca por meio desses serviços e na disseminação da informação com o Really Simple Syndication (RSS). 
A motivação para o tema central a ser abordado neste trabalho, se deu com a notória e visível rapidez com que a tecnologia da web se desenvolve e, como tal, pode ser útil em um ambiente que precisa acompanhar essa evolução, como é o caso das bibliotecas tradicionais e, até mesmo, as chamadas bibliotecas digitais. Cada mudança significativa que acontece no mundo virtual pode afetar diretamente o mundo real e o comportamento dos usuários. Estes podem ficar cada vez mais exigentes e desejosos de informação na mesma velocidade que a internet pode oferecer, com a mesma relevância dos melhores mecanismos de busca disponíveis.

O presente trabalho teve como objetivo identificar as tecnologias da web 2.0, que podem ser utilizadas como ferramenta na oferta de serviços e produtos no setor de referência. O método empregado para o desenvolvimento desta pesquisa foi a revisão de literatura e exemplos reais existentes na $w e b$, analisando a viabilidade da utilização dessas ferramentas nas bibliotecas brasileiras.

\section{A Web 2.0}

Nos Estados Unidos, a web entrou na vida das pessoas e se consolidou como um dos meios de comunicação mais poderosos. A web, desenvolvida por Bernes-Lee, organizava e representava os dados da rede de maneira mais visual, na qual os usuários leigos poderiam utilizá-la, como sendo apenas mais um programa processado em seu computador. Esse desenvolvimento evoluiu, criando os chamados navegadores ou "browsers", os programas utilizados como mediadores entre a web e o usuário.

A partir do estouro da "bolha" em 2001, quando várias empresas quebraram, devido à mudança do paradigma no comércio, no qual a internet passou a ser um dos principais meios de divulgação e de mercado financeiro, a própria web começou a sofrer mudanças, evoluindo para um novo conceito definido por O'Reilly (2005) como web 2.0 ou a segunda geração da web:

O conceito de Web 2.0 começou com uma conferência de brainstorming entre a O'Reilly e a MediaLive International. Dale Doughherty, pioneiro da Web e vice-presidente da O’Reilly, notou que, ao contrário de haver explodido, a Web estava mais importante do que nunca, apresentando instigantes aplicações novas e sites eclodindo com surpreendente regularidade. $\mathrm{E}$, o que é melhor, parecia que as companhias que haviam sobrevivido ao colapso tinham algo em comum. Será que o colapso pontocom marcou uma espécie de virada que deu sentido a uma convocação do tipo "Web 2.0"? (O'REILLEY, 2005, p. 1).

Desde a sua eclosão, em meados de 2004, a segunda geração de aplicações da web ou web 2.0, tem se consolidado como algo presente constantemente na vida das pessoas. Muitos ainda acreditam que essa 
denominação seja algo apenas comercial, que web 2.0 é apenas a evolução natural da web e que classificá-las em fases ou gerações nada mais é do que estratégias de marketing. Porém, estrategicamente ou não, a web 2.0 é algo real e que está presente na vida e no cotidiano de todos, mesmo daqueles que ainda não se deram conta disso.

A evolução das gerações da web se deu de maneira muito rápida. A primeira geração teve início no começo da década de 1990 , a segunda e atual surgiu em 2004 e já se fala na terceira geração, que será a web semântica, com recuperação inteligente do conteúdo disponibilizado na internet. A primeira geração da web, que durou até 2003, possuía uma interatividade entre conteúdo/usuário muito menor da que a segunda, que começou a se mostrar mais presente na rotina de utilização da internet.

Criar, participar e compartilhar são ações que o usuário da web 2.0 pode fazer com a mesma facilidade com que pode comprar uma revista em uma livraria. A interação é o novo lema da web e os sítios estão cada vez mais participativos, deixando que a opinião do usuário decida o rumo a ser tomado pelos administradores.

\section{0 serviço de referência}

Os serviços de referência sempre foram um setor importante das atividades de uma biblioteca. É nele que todo o trabalho interno e externo da biblioteca se concentra. Tudo que é feito em todos os outros setores, como a catalogação, indexação, processos técnicos, aquisição, entre outros, volta-se para o setor de referência, pois é nele que se encontra a razão final de toda existência de uma biblioteca: o usuário.

O atendimento ao usuário é o objetivo final de todo centro de informação. Essa atividade se desenvolve de tal maneira que atualmente existem certificados, como a ISO 9000, para unidades de informação que realizam um atendimento de qualidade ao usuário.

O serviço de referência serve como um mediador entre o conhecimento disponibilizado e o usuário que fará uso desse conhecimento, pois sem a participação do mediador a informação recebida, dificilmente seria eficiente ou de qualidade. A tradução da informação buscada para um documento que contenha a mesma informação é feita por profissionais que são especializados em pesquisar e atender à necessidade de informação.

Segundo Lancaster (2004):

Uma representação genérica das atividades da biblioteca, vistas pelos olhos de um avaliador, constitui um modo conveniente de se enfocar a avaliação dos serviços bibliotecários. Acredita-se que o objetivo de longo prazo da biblioteca seja produzir certos resultados na comunidade a ser atendida. [...] O insumo primário, ou seja, os recursos financeiros são usados para conseguir insumos secundários importantes, a saber, recursos informacionais (principalmente publicações de vários tipos), pessoal para utilizar esses 
recursos, e instalações físicas para armazenar o material, oferecer serviços e assim por diante. (LANCASTER, 2004, p. 1).

De fato, a biblioteca possui um objetivo final, que é conseguido por meio de dois insumos: o primário, que é a parte financeira, e o secundário, que são as atividades realizadas pela biblioteca para atingir seu objetivo final.

Dentro do insumo secundário, é importante frisar o papel essencial do usuário, que, de acordo com Lancaster, é representado pelo "pessoal para utilizar esses recursos" e, ainda, para usufruir dos serviços prestados pela junção dos insumos primários e secundários.

A biblioteca é o resultado desses dois insumos, que deve ter como objetivo final à comunidade de usuários a ser servida, como demonstra a Fig. 1.

Figura 1 - As atividades de uma biblioteca

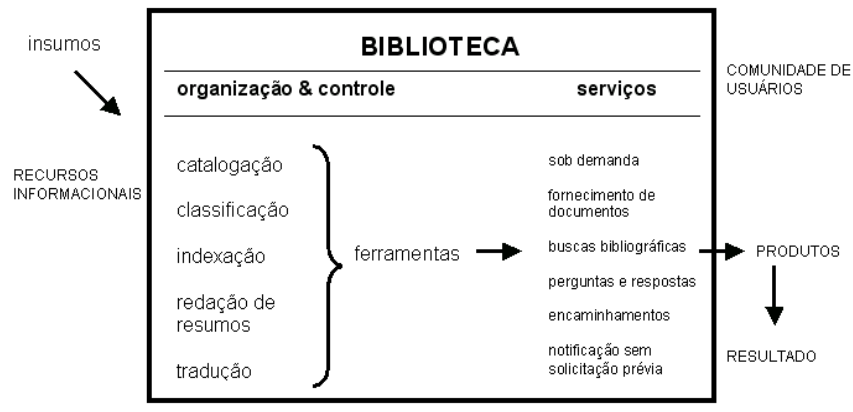

Fonte: LANCASTER (2004).

Cabe destacar que $\mathrm{o}$ aspecto importante a ser ressaltado diz respeito às cinco leis da biblioteconomia de S. R. Ranganathan (CUNHA; CAVALCANTI, 2008, p. 221), a saber: os livros são para usar; a cada leitor seu livro; a cada livro o seu leitor; poupe o tempo do leitor; e a biblioteca é um organismo em crescimento. Fica claro que para o grande mestre indiano que a biblioteca existe para servir ao usuário, com rapidez e eficiência, poupando, assim, o tempo do leitor. Portanto, a biblioteca é um organismo em crescimento, ou seja, é um organismo vivo que deve estar em constante evolução para que seus serviços não se tornem obsoletos.

\section{As Ferramentas da Web 2.0 no Serviço de Referência}

Os processos realizados nas bibliotecas estão interligados, fazendo com que um setor se complemente ao outro, no intuito de gerar os produtos e serviços para atender ao seu objetivo final, o usuário. Os aplicativos da web 2.0 estão se tornando um aliado no processo de 
geração desses serviços e produtos, como é apresentado nos exemplos a seguir.

\subsection{Ferramentas de Pesquisa}

Dentre as utilidades das ferramentas de pesquisa da web 2.0 estão as aplicações, que permitem aos usuários criar, editar ou adicionar conteúdos. A seguir, serão apresentados exemplos de como essas ferramentas podem atuar nas bibliotecas.

\subsubsection{Wikis}

Uma ferramenta inovadora que apenas começou a ser implantada nas bibliotecas é o wiki, totalmente colaborativa, pois permite aos usuários editarem qualquer texto, conforme seus interesses. A facilidade de utilização, que dispensa conhecimentos específicos de informática e tecnologia, atrai os internautas que podem fazer parte da elaboração de uma página na internet cooperativa, com um conteúdo formado por diversas opiniões e fontes de conhecimento.

Segundo Maness (2006):

Wikis são essencialmente webpages abertas, onde qualquer um que seja registrado na wiki pode publicar, acrescentar e mudar o conteúdo. Assim como os blogs, eles não têm a mesma confiabilidade de fontes tradicionais, freqüentes discussões sobre a Wikipédia (uma enciclopédia online onde qualquer usuário registrado pode escrever, acrescentar e editar artigos) no universo das bibliotecas demonstram isso; mas isto, é claro, não elimina o valor da Wikipédia, isso muda na biblioteconomia devido a complicadas instruções para desenvolvimentos de coleção e informação. A falta de revisão dos pares e a editoração é um desafio para bibliotecários, não que eles devam evitar o uso das wikis, mas eles deveriam entender que essa parte do processo depende somente deles. Wikis como um item numa coleção, e instruções para os usuários associados, são certamente parte do futuro das bibliotecas.

A partir da visão de Maness (2006), fica claro que as bibliotecas ainda estão resistentes ao uso das wikis, mas que a falta de certificação por parte do conteúdo não deveria ser um empecilho para a utilização das mesmas. Os profissionais da informação devem ser os responsáveis por validar a informação criada, editada e compartilhada no ambiente da sua biblioteca.

Outra dificuldade na utilização das wikis é a falta de literatura sobre o assunto. Um estudo realizado em 2006, por Matthies, Helmke e Slater, revela que até aquela data ainda não existiam artigos publicados sobre a utilização de wikis em bibliotecas que pudessem demonstrar a experiência 
de unidades de informação com a ferramenta. Entretanto, em 2009, já é possível encontrar alguns exemplos de seu uso. Os autores, como Maness (2006), defendem a força e pertinência dessa ferramenta em uma biblioteca tradicional e Frunkim (2005) apóia a utilização das wikis em bibliotecas digitais.

Um exemplo de utilização de wiki é o da Biomedic Library da University of South Alabama ${ }^{1}$, que possui uma wiki sobre temas biomédicos, como instrumento de pesquisa para os usuários da biblioteca. Outros exemplos são as da University of Sydney ${ }^{2}$ e Charles Stuart University $^{3}$, ambas na Austrália. As bibliotecas buscaram criar essa ferramenta para contribuir com mais instrumentos de pesquisa para seus usuários, além dos já tradicionais fornecidos em material impresso (ver Fig. 2).

Figura 2 - University of Sydney - Meta Wiki

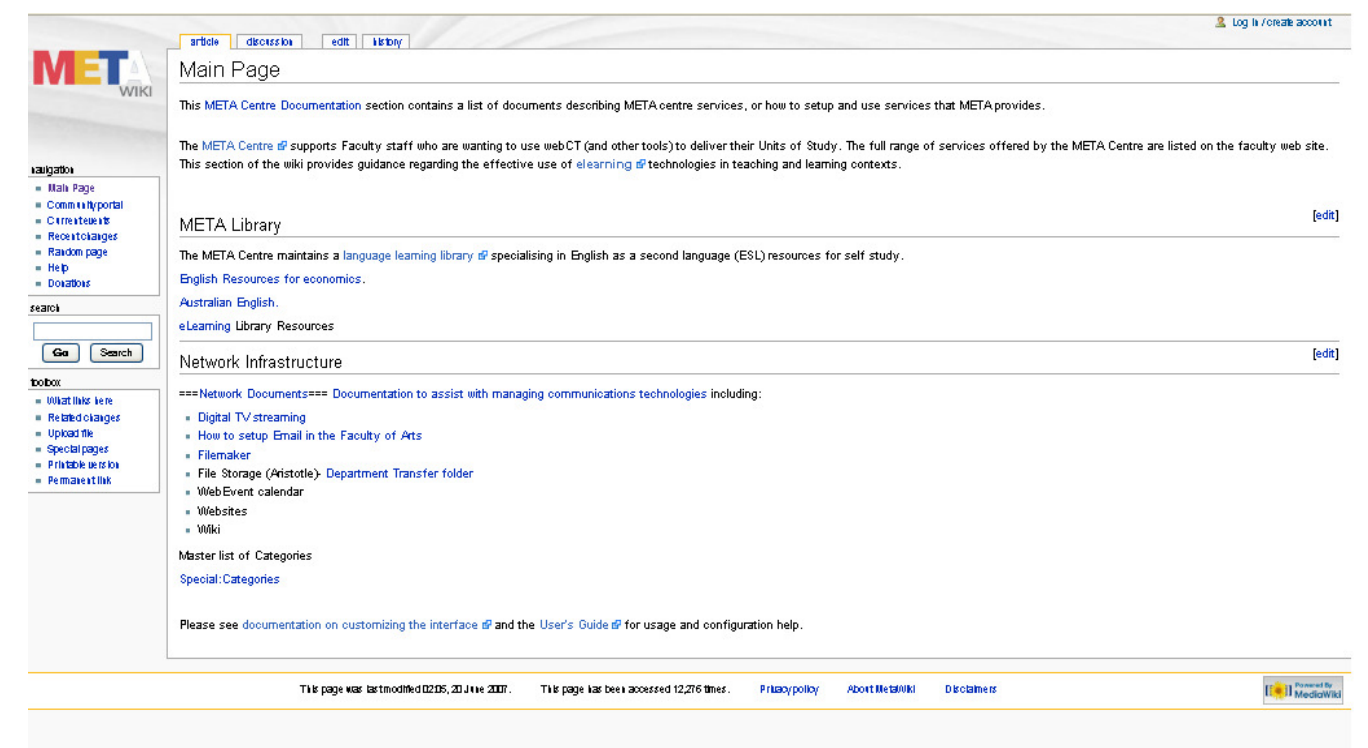

Fonte: UNIVERSITY OF SYDNEY (2011).

Outra iniciativa interessante são as bibliotecas do Baruch College ${ }^{4}$ e Butler University Libraries ${ }^{5}$, que criaram uma wiki de referências para ajudar os usuários nas pesquisas de determinados assuntos, ou seja, funciona como uma base de dados de referências colaborativa. Sempre que um usuário registrado encontrar uma referência interessante sobre determinado assunto, ele pode adicioná-la na base para compartilhá-la com outras pessoas. Essa iniciativa aumenta as fontes de pesquisa disponíveis para os estudantes destas universidades.

\footnotetext{
1University of South Alabama. Biomedic Library. Disponível em: < http://usabiomedmatters.wikidot.com/> Acesso em: 14 fev. 2012. 2University of Sydney. Meta Wiki. Disponível em: <http://wiki.arts.usyd.edu.au/meta/index.php/Main Page>. Acesso em: 14 fev. 2012.

3Charles Stuart University. Division of Library Service. Disponível em: <http://www.csu.edu.au/division/library/] >. Acesso em: $14 \mathrm{fev} .2012$.

4 Baruch College. William and Anita Newman Library. Disponível em:

<http://newman.baruch.cuny.edu/index.php>. Acesso em: 14 fev. 2012.

5Butler University. University Libraries. Disponível em: <http://www.butler.edu/library/>. Acesso em: 14 fev. 2012.
} 
Por meio dos exemplos citados é possível perceber como uma wiki pode ser útil na biblioteca, seja para criar conteúdos colaborativos, manuais ou bases de referências. O conteúdo desenvolvido, por abranger um universo ilimitado de pessoas, envolve também a biblioteca com seu usuário, que participa ativamente do processo de criação e gerenciamento de conteúdo. Iniciativas desse porte podem ajudar bibliotecas do mundo todo a aumentar sua atividade online e fazer crescer a interação usuário/biblioteca; principalmente, fornecer alternativas para as fontes de informação tradicionais disponibilizadas.

\subsubsection{Flickr}

Ao contrário do Facebook e do YouTube, segundo a literatura estudada, o Flickr demonstra ser muito mais aceito pela comunidade da Ciência da Informação na utilização desse serviço, em uma biblioteca.

Dentre as possibilidades de utilização do Flickr nas bibliotecas, Houghton-Jan (2005) cita as seguintes: licenciar as imagens, incluir tags nas imagens, fazer coleções particulares, acompanhar quantas pessoas visualizam cada imagem, permitir comentários, entre outras.

Já Stephens (2009), lista 10 maneiras para se utilizar o Flickr:

1) editar o perfil e fazer contatos, ou seja, colocar no perfil da biblioteca no Flickr a URL, missão, informações, contatos e procurar outras bibliotecas da mesma área para fazer contatos;

2) colocar tags (etiquetas) nas imagens do perfil com localização geográfica da biblioteca, bem como nome, universidade, escola ou instituição a qual pertença para facilitar a busca. Dessa maneira, usuários que busquem tags sobre sua cidade ou região poderão encontrar informações sobre bibliotecas que estejam perto dele;

3) divulgar imagens via RSS. Cada conta, tag ou grupo no Flickr possui um RSS Feed, que pode ser utilizado para divulgar aos usuários as últimas atualizações do perfil. O Flickr permite, também, que as atualizações sejam divulgadas em sítios web pessoais, por meio de um código HTML;

4) criar conjuntos de informações sobre programas, eventos e especialidades através da ferramenta de aplicativos do Flickr;

5) hospedar imagens do blog ou sítio web da biblioteca por meio do código HTML. As imagens hospedadas através dos links no Flickr podem ser estáticas ou dinâmicas, significando que pode ou não ser permitido ao usuário comentar ou incluir tags na imagem, na página do Flickr;

6) utilizar notas para links HTML. Usando a ferramenta de adicionar notas é possível inserir um link em sítios web, blogs ou catálogos, permitindo ao usuário uma navegação virtual em 
várias bibliotecas diferentes, de acordo com os links colocados;

7) motivar os usuários com imagens, ferramentas dinâmicas e hiperlink; eles são incentivados a comentar e complementar o conteúdo postado pela biblioteca;

8) compartilhar a história da biblioteca, postando imagens da biblioteca ao longo dos anos é possível montar uma história interativa e, ainda, permitir aos usuários que compartilhem suas próprias memórias, acrescentando mais informações à história da instituição;

9) utilizar algumas das ferramentas do Flickr para fazer gráficos com estilo. Muitas bibliotecas já possuem seus cartões visitas ou pôsteres, criados com a ajuda do Flickr. Elas também postam, entre outros, capas históricas de revistas e pôsteres de filmes; e

10) permitir acesso ao Flickr nos computadores das bibliotecas. Por motivos de segurança, muitas instituições bloqueiam o acesso a diversos tipos de sítios, inclusive ao Flickr.

Outros exemplos de utilização do Flickr que ainda podem ser citados são: divulgação das novas aquisições da biblioteca, postando as capas dos materiais para que os usuários visualizem; e divulgação de imagens históricas que não podem ser manuseadas devido à idade do material. De fato, citando novamente a Library of Congress $^{6}$ (LC), ela digitalizou e disponibilizou em seu perfil do Flickr na web, centenas de imagens históricas, inclusive do Brasil, e as organizou por álbuns, para facilitar a busca por interesse. Assim como no YouTube, todo o material disponibilizado pela biblioteca possui informações de copyright, formato, notas, autoria, data e indexação. Existem fotos de Abraham Lincoln, isto é, álbuns com imagens, fotos cromáticas de paisagens do planeta, panorâmicas da Primeira Guerra Mundial, imagens históricas de Minas Gerais, entre outros.

Como podem ser constatadas pelos exemplos, as possibilidades de utilização do Flickr são variadas, cabendo apenas à biblioteca descobrir de que maneira as ferramentas do Flickr Ihes podem ser úteis.

\subsubsection{YouTube}

O YouTube é considerado a maior comunidade de vídeos da internet. Paula Webb (2007) menciona algumas das maneiras que essa ferramenta poderia ser utilizada em uma biblioteca. Segundo ela, uma das

6 Library of Congress. Historic Photos. Disponível em:

$<$ http://www.flickr.com/photos/library of congress/collections/72157601355524315/>. Acesso em: 14 fev. 2012. 
possibilidades de uso para o YouTube é que ele seja um "depósito para vídeos instrucionais", que poderiam ser acessados através de um link, no sítio da biblioteca. Ou, ainda, uma maneira de complementar o conteúdo do acervo, utilizando vídeos que não são de autoria da biblioteca e que não pertencem a ela, para acrescentar algum conteúdo disponibilizado, como é citado no artigo, o exemplo da America's Career InfoNet ${ }^{7}$, que lista os vídeos sobre as diferentes profissões que existem no YouTube para ilustrar seu sítio e facilitar o entendimento do conteúdo, acrescentando-se, assim, mais um recurso audiovisual para os usuários.

A mesma autora observa, ainda, como parte da utilidade do YouTube, que a biblioteca poderia criar um manual com recurso audiovisual, com instruções passo a passo, para a utilização da biblioteca; guia de uso para estudantes; tutoriais para alunos e usuários de como usar a base de dados; tutoriais sobre o software utilizado pela biblioteca e como usá-lo. Outro exemplo citado no artigo é o da Valdosta State University $^{8}$, que criou um vídeo sobre "Como encontrar uma mesa de referência". O vídeo se inicia na entrada da biblioteca e segue o caminho que deverá ser percorrido pelo usuário até os balcões de atendimento, facilitando a visualização do estudante, que se sentirá familiarizado com o ambiente, antes mesmo de ter entrado na biblioteca.

A Library of Congress $^{9}$ mantém uma conta no YouTube, intitulada Library of Congress Channel, com dezenas de vídeos antigos restaurados pela biblioteca e que são considerados raros, como vídeos filmados por Thomas Edison, datados de 1897, e apresentações culturais, como a Imperial Japanese Dance, de 1894. Todos esses vídeos apresentam suas descrições completas, fontes e copyrights, para não infringir os direitos dos autores.

Webb (2007) lembra, ainda, que é importante que os administradores das bibliotecas não tenham medo de utilizar essas ferramentas por não serem convencionais, pois a sua utilização prova à sociedade que as bibliotecas estão prontas para o século XXI.

\subsection{Ferramentas de Relacionamento Social}

Os sítios de relacionamento social são ferramentas que permitem uma interação com usuário, dificilmente conseguida com o uso de outros meios de comunicação. Exemplos de utilização são apresentados a seguir.

\subsubsection{Facebook}

A utilização do Facebook em bibliotecas tem sido motivo de muita discussão na comunidade biblioteconômica, que divide opiniões sobre o sítio ser mais uma ferramenta para auxiliar na divulgação dos produtos e

7America's Career InfoNet. CareerOneStop. Disponível em:

<http://www.acinet.org/videos/COS_videos.asp?nodeid=27> . Acesso em: 14 fev. 2012.

8 Valdosta State University. Odum Library. Disponível em: <http://www.valdosta.edu/library/>. Acesso em: 14 fev. 2012.

9 Library of Congress. Library of Congress Channel. Disponível em:

<http://www.youtube.com/user/LibraryOfCongress >. Acesso em: 14 fev. 2012. 
serviços das bibliotecas ou, apenas, uma rede social sem utilidade para fins profissionais.

De acordo com Secker (2008), alguns membros diretores da Libraries and Social Software in Education (LASSIE) se mostraram contrários à utilização do Facebook dentro das bibliotecas, principalmente por motivos de segurança da informação que, segundo eles, é indiscriminada, podendo qualquer pessoa, mesmo que fora dos interesses da biblioteca, acessar suas informações.

Outro ponto relatado pelo mesmo autor diz respeito ao fato de que muitos profissionais da informação não acham apropriada a utilização de uma rede social na internet para os serviços bibliotecários. Segundo o autor, essas redes têm fundamento puramente social, com a função de ser apenas uma distração para as pessoas, não tendo, assim, valor para utilização profissional.

Entretanto, existem profissionais que defendem a utilização do Facebook como ferramenta de divulgação da biblioteca, devido às suas inúmeras possibilidades oferecidas. Um participante do Facebook pode acrescentar diversos aplicativos em seu perfil, além de criar listas para compartilhar informações com pessoas de uma rede e com interesses específicos.

O Facebook permite a utilização do Delicious, como bookmarking, e que um membro divulgue suas fotos em seu perfil por meio do Flickr. Além da postagem de vídeos, criação de álbuns, feed de notícias detalhadas de tudo que acontece com as pessoas da sua rede, criação de grupos de interesses específicos e utilização, entre outros, de calendário para criação de eventos, utilização de notas e divulgação de links de interesse para divulgação.

Todas essas ferramentas utilizadas com responsabilidade e interesse profissional podem, segundo Secker (2008, p. 8), ser aliadas dentro de uma unidade de informação, como são demonstrados a partir dos exemplos a seguir:

a) LibGuides Librarian ${ }^{10}$ : permite ao usuário exibir os guias de seu perfil e, também, busca em catálogos de bibliotecas que tenha perfil no Facebook;

b) Facebook Librarian"1: funciona como um "fale conosco" ou "pergunte a um bibliotecário", por meio das pessoas que tenham a biblioteca fornecedora do serviço em seu perfil; e

c) Books iRead ${ }^{12}$ : esse é considerado o maior aplicativo relacionado a livros do Facebook. Nele, é permitido ao usuário compartilhar suas preferências de leitura, informando quais livros já leu, quais gostaria de ler, quais nunca leria e fazer

10 LibGuides Librarian. Disponível em: <http://www.facebook.com/apps/application.php?id=2409492434>. Acesso em: 14 fev. 2012.

11 Facebook Librarian. Disponível em: <http://www.facebook.com/group.php?gid=2210901334>. Acesso em: 14 fev. 2012.

12Books iRead. Disponível em:

<http://www.facebook.com/s.php?q=Books+iRead\&init=quick\#/apps/application.php?id=2406120893\&ref=s $>$. Acesso em: 14 fev. 2012. 
uma classificação de livros de acordo com critérios estabelecidos pelo próprio usuário.

Dessa maneira, é possível perceber quais são as utilidades do Facebook em uma biblioteca. Entretanto, apesar das ideias serem promissoras, é preciso estudá-las com cuidado e avaliar se a utilização da rede é mesmo viável para a instituição. Apesar de aparentemente parecer um aliado, se usado indiscriminadamente, o perfil da biblioteca pode rapidamente se tornar inutilizado ou sobrecarregado com informações inúteis para os interesses da biblioteca. Ao contrário, se utilizado com discernimento, pode ser uma rede de compartilhamento de informações valiosas e de crescimento contínuo para a biblioteca.

\subsubsection{Twitter}

O uso do Twitter nas bibliotecas ainda está em processo de adaptação. Entretanto, já existem alguns estudos de casos em bibliotecas dos Estados Unidos, pioneiras na utilização destas ferramentas da web 2.0.

A Missouri River Regional Library ${ }^{13}$ está utilizando o Twitter para se comunicar com a comunidade local. Tudo que acontece na biblioteca está sendo colocado na ferramenta, para que seus "seguidores" (termo designado para aqueles que adicionam um perfil do Twitter para acompanhar suas atualizações) possam ter acesso a todas as novidades da biblioteca, como novas aquisições de base de dados, eventos promovidos pela biblioteca, alterações no funcionamento ou horários. Outra funcionalidade do Twitter é o fato de que o aplicativo possui RSS feed, outra ferramenta que tem feito muitos adeptos nos centros de informação.

De acordo com Arnal (2008), o blog BusEmpresarials da Universidade Autônoma de Barcelona ${ }^{14}$ também utiliza 0 Twitter como ferramenta de divulgação das notícias mais breves, que podem ser visualizadas por meio de uma assinatura RSS feita pelo usuário no blog.

Apesar do sucesso do Twitter na internet ser indiscutível, os centros de informação ainda estão receosos ao se depararem com tal ferramenta, seja pelo desconhecimento dos profissionais da informação do potencial de um microblog como o Twitter no auxílio à divulgação das atividades das bibliotecas. Mas, essa visão está se modificando como demonstram os exemplos dados por bibliotecas que buscam alternativas inovadoras, como a utilização desses microblogs para divulgação de seus produtos e serviços.

\subsubsection{Social Bookmarking}

13 Missouri River Regional Library. Disponível em: <http://twitter.com/mrrl>. Acesso em: 14 fev. 2012. 14Universidade Autônoma de Barcelona. Disponível em: <http://blogs.uab.cat/busempresarials/>. Acesso em: 14 fev. 2012. 
Umas das aplicações da web 2.0 que mais tem se destacado é o social bookmarking, uma maneira de se "guardar" todos os sítios de interesse e que podem ser resgatados de qualquer computador.

A Ithaca College Library ${ }^{15}$ é uma das bibliotecas que serve de exemplo para ilustrar a utilização do social bookmarking. Gilmour e Stickland (2009) explicam como e por que essa biblioteca adotou esse aplicativo e está investindo em divulgá-lo para melhorar os serviços para seus usuários.

Os autores relatam que o trabalho com o Delicious, uma das ferramentas mais famosas de social bookmarking disponíveis na web, começou quando um docente da faculdade solicitou que os bibliotecários adicionassem ao cabeçalho de assuntos da Library of Congress (LC) os termos relacionados à presença de estereótipos asiáticos em filmes de Holywood. Em resposta a sua solicitação, a LC informou que isso era impraticável e contrário à boa prática de catalogação, além de não corresponder aos objetivos da lista de cabeçalhos de assuntos da instituição.

Como esse não fora o primeiro pedido incomum dos docentes da universidade, os bibliotecários resolveram desenvolver um cabeçalho de assuntos não tão tradicional quanto o da LC, por meio do social bookmarking. Disponibilizando o aplicativo do Delicious em sua página na internet, a biblioteca pode utilizar tags para descrever páginas interessantes sobre o assunto pesquisado e salvá-las para formar uma base com todos os documentos relevantes sobre diversas pesquisas solicitadas pelos docentes. Dessa maneira, a colaboração entre os interessados faria a pesquisa se tornar mais eficiente, uma vez que qualquer usuário poderia adicionar sua própria tag ou página conforme achasse relevante. O resultado do trabalho foi muito satisfatório e, agora, a biblioteca utiliza essa técnica de social bookmarking sempre que é solicitado.

\subsection{Ferramentas de divulgação}

A divulgação de informação na internet muitas vezes se dá de maneira conturbada. Algumas ferramentas surgiram para tentar personalizar esse fornecimento de informação, como é o caso dos blogs e do RSS.

\subsubsection{Blogs}

O blog é uma ferramenta totalmente interativa, que permite compartilhar conteúdo de maneira simples e fácil como são baseadas as ferramentas da web 2.0. Ele faz parte da "cultura popular" dentre as pessoas que têm acesso à internet, são exemplo que, segundo Arnal (2008), mostram que tecnologia da web está ao alcance de quase todas

15Ithaca College. Ithaca College Library. Disponível em: <http://www.ithaca.edu/library/>. Acesso em: 14 fev. 2012. 
as bibliotecas e são uma maneira de comunicação com a menos rígida que a exigida por sítios institucionais.

As bibliotecas têm utilizado os blogs como instrumento de divulgação das suas notícias, ou como descreve a Biblioteca da Universidade de Aveiro $^{16}$ (Fig. 4) em Portugal: "um meio de contato com os nossos utilizadores, uma forma de partilhar a vida das bibliotecas da UA, um caminho para a divulgação de recursos e ferramentas para a aprendizagem e investigação." (UNIVERSIDADE DO AVEIRO).

Figura 3 - Blog da Biblioteca da Universidade do Aveiro (Portugal)

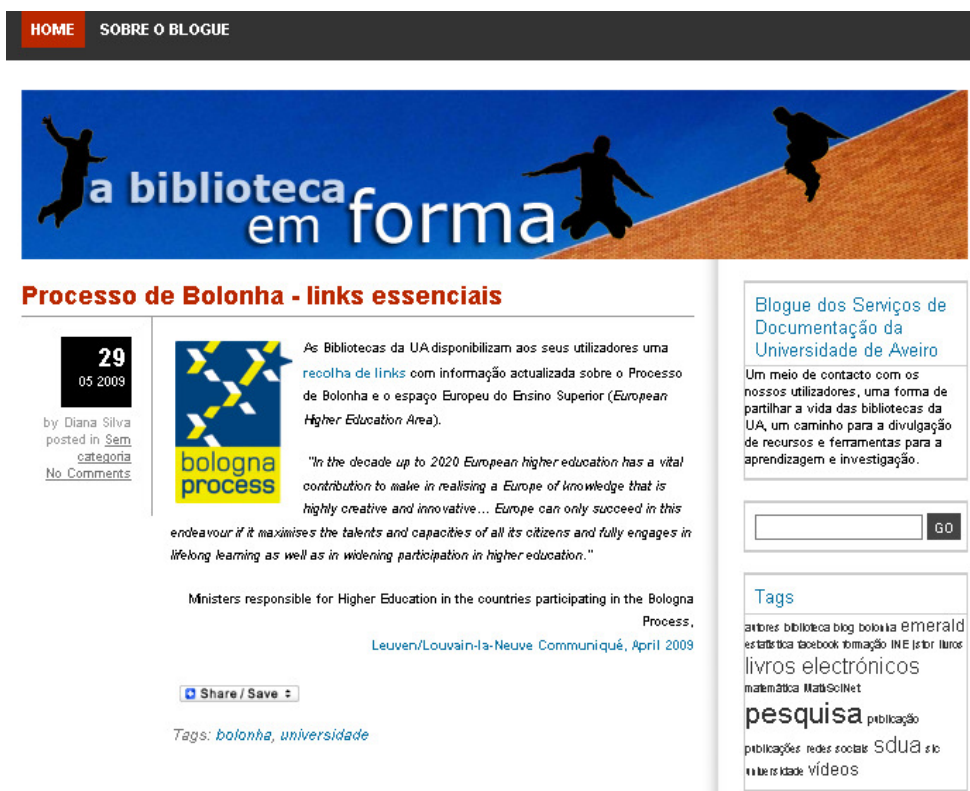

Fonte: UNIVERSIDADE DO AVEIRO (2011).

Os blogs são ferramentas úteis às bibliotecas, na medida em que os serviços e as notícias disponibilizadas podem ser repassados aos usuários, de maneira que eles possam responder e comentá-las, dando um retorno sobre as iniciativas da biblioteca. Arnal (2008) diz como os blogs devem:

"[...] abrir espaços de comunicação interpessoal, buscar uma conversação com o leitor, mas uma comunicação unidirecional. Devem demonstrar que comunicação pode ser mais do que apenas o tom formal e institucional de uma biblioteca e que podem ser úteis e apreciadas pelos leitores." (ARNAL, 2008, p. 11).

Outra biblioteca que utiliza o blog como meio de comunicação e interação com seus usuários é a Biblioteca do Agrupamento Vertical de Escolas de Vila Pouca de Aguiar Sul (Portugal) ${ }^{17}$, que transmite, de

16 UNIVERSIDADE DO AVEIRO. Serviços de Biblioteca, Informação Documental e Museologia. Blogue: $A$ Biblioteca em forma. Disponível em: <http://blogs.ua.pt/biblioteca/>. Acesso em: 14 fev. 2012.

17 Agrupamento Vertical de Escolas de Vila Pouca de Aguiar Sul (Portugal). Biblioteca. Disponível em: <http://bibliotecaspacosbrandao.blogspot.com/>. Acesso em: 14 de fev. 2012. 
maneira mais descontraída e informal, as notícias sobre os eventos já realizados e a serem realizados, além de notícias sobre diversos assuntos.

Segundo Fichter (2003), existem inúmeras maneiras como os blogs de bibliotecas podem ser usados para divulgá-las: promover os eventos da biblioteca, apoio aos usuários mais frequentes, engajar a comunidade local, apoiar a comunidade que já utiliza a biblioteca, criar novos laços atraindo novos usuários, entre outros.

Dentre as possibilidades de utilização dos blogs, é preciso que as bibliotecas encarem a iniciativa de mantê-lo com seriedade, pois, como relata Crawford (2009), eles podem, muitas vezes, se tornar inúteis rapidamente. Segundo o autor, para que um blog seja bem sucedido em seus objetivos é necessário: a) um propósito bem definido para nortear as informações que serão disponibilizadas; b) comprometimento para com os usuários que o frequentarão; c) publicidade, antes de tudo é preciso que a biblioteca divulgue a existência do blog para seus usuários; d) começar de baixo, não pensar que o blog deve ser grande e conter uma quantidade exagerada de informações, é preciso discernimento dos profissionais para não sobrecarregar a página com informações que muitas vezes serão inúteis para o público. Isso fará com que o mesmo se afaste e pare de acessar o blog.

Outro ponto importante ressaltado por Crawford (2009) é que só devem ser postadas notícias novas quando se tem alguma coisa relevante para se dizer, nunca se poste apenas por postar. As bibliotecas não devem também pressupor que os usuários irão até o sitio apenas porque ele existe, é necessário que haja interesse por parte do público. Elas não devem igualmente pressupor que as notícias receberão comentários. Esse tipo de postura dos usuários deverá surgir com o tempo, à medida que o blog se consolidar.

Esses meios de utilização dos blogs possibilitam, principalmente, uma aproximação da biblioteca com seu usuário, permitindo a coleta de dados importantes sobre as opiniões dos usuários em relação às atividades desenvolvidas pela biblioteca e como elas estão sendo trabalhadas.

\subsubsection{RSS}

O Really Simple Syndication (RSS) é uma das ferramentas que melhor caracterizam o conceito de web 2.0. Funciona como um feed de notícias para blogs e outros tipos de sítios, facilitando o processo pelo qual a informação passa até chegar ao usuário. O RSS também proporciona a atualização das notícias em tempo real e com informações direcionadas, já que para sua utilização é necessário que o usuário se inscreva nas determinadas áreas de informação pelas quais ele se interessar. Dessa 
maneira, a informação é fornecida de modo personalizado, filtrando o que o usuário vai receber.

Sua utilização pode ser muito importante para auxiliar um determinado serviço que uma biblioteca deve proporcionar, entre outros, os seguintes:

1) criar um RSS feed para novas aquisições no catálogo em linha;

2) criar um RSS feed ligado ao cadastro de cada usuário na biblioteca para notificações de materiais atrasados;

3) criar um RSS feed para novos programas e eventos postados no sítio da biblioteca;

4) criar um RSS feed para o boletim eletrônico da biblioteca;

5) criar um RSS feed para informar a imprensa e outras mídias;

6) criar um RSS feed para informar sobre os dias que a biblioteca estará fechada e fechamentos de emergência;

7) criar um RSS feed para vagas de emprego na biblioteca;

8) inscreverem-se alguns feeds RSS, como notícias locais, e compartilhar o conteúdo no sitio da biblioteca. Isto poderia ser incluído em uma página que contém outros recursos locais e links locais;

9) inscrever RSS feeds de interesse para os clientes da biblioteca e compartilhar o conteúdo personalizado de cada cliente na página da biblioteca. Os clientes podem optar por acessar RSS feeds selecionando sua conta com informações sobre: assinatura de bases de dados, correio eletrônico e mensagem instantânea com um bibliotecário; e

10) inscrever RSS feeds de profissionais e compartilhar com a equipe da biblioteca na sua rede interna. (2008):

Como formas de utilização do RSS em bibliotecas, para Almeida

Boa parte das bibliotecas estrangeiras está criando canais RSS para informar seus usuários sobre novos itens incorporados às suas coleções. Um bom exemplo da apropriação deste recurso pode ser verificado nos serviços oferecidos pela biblioteca da Universidade de McMaster (Canadá), que disponibiliza vários canais RSS para divulgar seus serviços, eventos e novas aquisições, segundo as áreas de interesse de seus estudantes, docentes e pesquisadores. A biblioteca mantém, ainda, canais específicos para atualização de documentos diversos, mapas, eventos, novas aquisições, entre outros. Outra iniciativa bem 
sucedida é mantida pelo serviço de distribuição de sumários da MIT Libraries. (ALMEIDA, 2008, p. 9).

Ainda segundo Almeida (2008, p. 9): "outra aplicação possibilitada pelo uso de RSS é a republicação de conteúdos originados por outras fontes nas páginas da biblioteca ou serviços de informação". Isto propicia à biblioteca uma compilação de conteúdos de interesse dos usuários, mas que tenham sido produzidos por terceiros, para ampliar e diversificar as fontes de informação disponibilizadas.

Exemplos de bibliotecas que tem utilizado o RSS em suas páginas da internet são: Library of Congress ${ }^{18}$, que alimenta em seu blog mais de 35 tipos diferentes de assuntos, entre os quais: notícias gerais da biblioteca, atualizações do sítio da biblioteca, eventos, tópicos como direitos autorais, preservação digital, assuntos legais, legislação, jornais e jornalismo, poetas e poesia, ciências, histórias dos veteranos, projetos visuais. Além de feeds específicos para bibliotecários e professores.

A biblioteca da University of Michigan ${ }^{19}$ alimenta feeds sobre guias bibliográficos, notícias, eventos e exposições da biblioteca. Outra biblioteca universitária americana que permite o serviço de RSS é a do Massachussets Institute of Technology ${ }^{20}$ que disponibiliza feeds específicos para cada curso do instituto, além de notícias gerais, atualizações da Classificação Decimal de Dewey e podcasts.

A University of Baylor Library ${ }^{21}$ atualiza semanalmente todas as novas aquisições e as organiza por áreas de interesse, permitindo que o usuário escolha somente as áreas do conhecimento que lhe sejam pertinentes. Kansas State University Library ${ }^{22}$ : novos livros por assunto ou tipo de material (livro, CD ou DVD)

No Brasil a iniciativa de utilizar o feed RSS ainda é tímida, mas já podem ser encontradas em bibliotecas como a do Senado Federal $^{23}$ e a Biblioteca Digital de Teses e Dissertações do IBICT $^{24}$ (Fig. 4).

\footnotetext{
18 LIBRARY OF CONGRESS. RSS Feeds and Email Subscriptions. Disponível em: <http://www.loc.gov/rss/>>. Acesso em: 14 de fev. 2012.

19 University of Michigan. University Library. Research guides. Disponível em:

<http://guides.lib.umich.edu/content.php?pid=24734>. Acesso em: 14 fev. 2012.

20Massachussets Institute of Technology. MIT Libraries. RSS Feeds by topic. Disponível em: < http://newslibraries.mit.edu/blog/rss-feeds/> Acesso em: 14 fev. 2012.

21University of Baylor. Baylor University Libraries. Disponível em:

$<$ http://www.baylor.edu/lib/electrres/index.php?id=37457>. Acesso em: 14 fev. 2012.

22 Kansas State University. Libraries. Disponível em: <http://ksulib.typepad.com/>. Acesso em: 14 fev. 2012. 23 Brasil. Senado Federal. Biblioteca. Disponível em: <http://www.senado.gov.br/sf/biblioteca/>. Acesso em: 14 fev. 2012.

24IBICT. Biblioteca Digital de Teses e Dissertações. Disponível em: < http://bdtd.ibict.br/>. Acesso em: 14 fev. 2012.
} 
Figura 4 - RSS Feed da Biblioteca Digital de Teses e Dissertações/IBICT

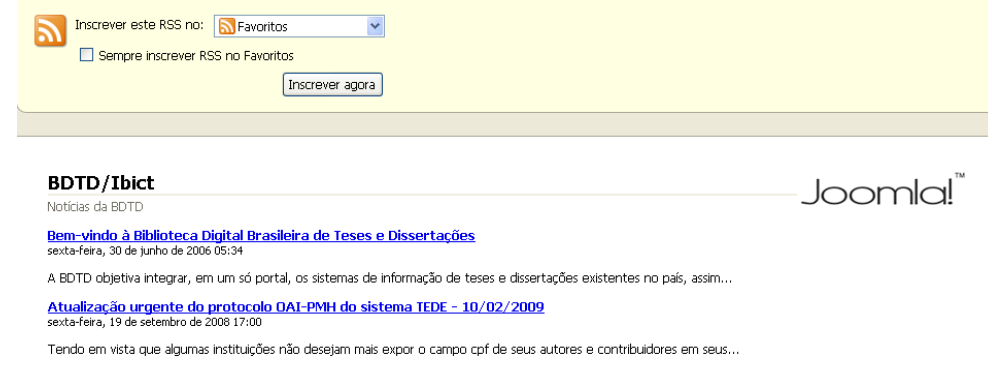

Fonte: IBICT (2011).

\subsection{Mensagens Instantâneas}

Os serviços de mensagens instantâneas (instant messaging, IM) se tornou um dos maiores trunfos da web 1.0 e uma das ferramentas que mais evoluíram ao longo dos anos, ajudando a consolidar o termo web 2.0, devido a certas características que começaram a apresentar conforme evoluíam.

Logo o interesse por esse tipo de ferramenta surgiu na comunidade bibliotecária, como apresenta Maness (2006):

Esta tecnologia tem sido rapidamente adotada pela comunidade bibliotecária. Mais comumente conhecida como instant messaging (IM), permite uma comunicação textual em tempo real entre indivíduos. As bibliotecas têm começado a empregar e promover serviços de "chat reference", onde usuários podem sincronicamente se comunicar com bibliotecários muito mais do que o fariam em um atendimento cara a cara (MANESS, 2006).

De acordo com este autor, as bibliotecas viram potencial nessa ferramenta, principalmente no que diz respeito ao serviço de referência, no qual poderia ser acrescentado outro tipo de atendimento, fora os já tradicionais do balcão, face a face. De fato, esse tipo de atendimento pode ser muito instrutivo, tanto para a biblioteca quanto para o usuário. Existem diversos tipos de usuários, como relatam os estudos de usuários, e para certos tipos esse atendimento impessoal apresenta uma possibilidade de comunicação e interação muito maior entre usuáriobibliotecário.

Maness (2006) relata, ainda, que:

Mais do que o usuário tem o costume de definir a biblioteca física pela presença do bibliotecário, chat reference vem se tornando mais persuasivo e pode prover uma situação similar no mundo da web. Em tempo talvez não tão distante o chat reference pode ter um lugar dentro da estrutura da rede de 
trabalho da biblioteca, provendo uma experiência sem fronteiras (MANESS, 2006).

Percebe-se, então, que a biblioteca deve utilizar as tecnologias da web em seu favor e de seus usuários para desenvolver atividades complementares aos serviços prestados. Dessa forma, as bibliotecas poderão se familiarizar com os anseios de seus usuários e formarem uma política de atendimento mais eficiente e de qualidade.

Breeding (2003) diz que uma das vantagens do sistema de mensagens instantâneas sobre os tradicionais serviços de correio eletrônico adotados pelas bibliotecas, nos quais o usuário não sabe quando obterá resposta, ao contrário, no IM, desde que a biblioteca esteja em linha ou disponível, dependendo do programa utilizado, o usuário sabe que a resposta a sua demanda será imediata. Esse método facilita a finalização do atendimento, já que por correio eletrônico, muitas vezes, as dúvidas não são resolvidas na primeira conversa, prolongando o processo e desmotivando o usuário, o que prejudica o atendimento.

O autor defende, ainda, o fato de que a nova geração está completamente envolvida com o IM, devido ao sucesso desse tipo de serviço, junto à maioria das crianças e jovens com acesso a internet, que são adeptos e dominam essa ferramenta. Para Breeding (2003), as bibliotecas podem se aproveitar desse envolvimento para aumentar a interação entre a biblioteca e os jovens.

A experiência da Ohio Public Library Information Network ${ }^{25}$, segundo York (2009), revela que o serviço de mensagens instantâneas cresceu de maneira inesperada na biblioteca. Em 2004, quando o serviço começou a ser disponibilizado, cerca de 60 pessoas o utilizavam por mês; em 2009, a biblioteca completou 500.000 atendimentos. Segundo a autora, as dúvidas são variadas, vão desde pessoas perguntando sobre o catálogo da biblioteca até jovens pedindo ajuda em seu dever de casa. Para conseguir atender a demanda, a biblioteca oferece o serviço 24 horas por dia, sete dias por semana, exceto nos feriados.

O sítio Library Sucess ${ }^{26}$ lista inúmeras bibliotecas que utilizam o serviço de mensagens instantâneas. Cada uma utiliza a política mais adequada a seus serviços, algumas, como a University of California San Diego Science and Engineering Library ${ }^{27}$, disponibilizam o serviço em dias de semana de 10 às 17 horas, por meio do AIM e Yahoo Messenger. Ou, ainda, a Colorado College Tutt Library ${ }^{28}$, que disponibiliza o serviço por meio do AIM, Yahoo Messenger e MSN Messenger durante todo o tempo em que tiver um bibliotecário na mesa de referência.

Apesar de parecer promissor, Breeding (2003) adverte quanto a algumas desvantagens do uso do IM:

25 Ohio Public Library Information Network. Disponível em: <http://www.oplin.lib.oh.us/>. Acesso em: 14 fev. 2012.

26 Library Sucess. Disponível em: <http://www.libsuccess.org/index.php?title=Online Reference>. Acesso em 14 fev. 2012.

27 University of California San Diego. Science and Engineering Library. Disponível em:

<http://libraries.ucsd.edu/locations/se/>. Acesso em: 14 fev. 2012.

28 Colorado College. Tutt Library. Disponível em: <http://www.coloradocollege.edu/library/index.php/>. Acesso em: 14 fev. 2012. 
Algumas das maiores vantagens do uso de mensagens instantâneas que a fazem atrativos para comunicação individual, podem causar problemas quando usadas no trabalho. A falta de sistemas de autenticação dos serviços e escassez de responsabilidade na utilização podem trazer problemas em ambientes empresariais. (BREEDING, 2003, p. 38)

Como aponta o autor, é preciso ter cuidado na disponibilização dos serviços de mensagens instantâneas, que pode facilmente se tornar um transtorno para a instituição, ao invés de ser mais um aliado no atendimento aos usuários.

\section{Considerações finais}

Buscando identificar as tecnologias da web 2.0, que podem ser utilizadas como ferramenta na oferta de serviços e produtos na referência para o atendimento aos usuários, pode-se perceber a clara vantagem de países desenvolvidos na utilização dessas iniciativas em relação ao Brasil, principalmente nos Estados Unidos. Bibliotecas como a Library of Congress, que foi citada em alguns exemplos, mas poderia ter sido mencionada em $90 \%$ das ferramentas estudadas, mostram como as bibliotecas americanas estão dispostas a adotar novas tecnologias para desenvolver um atendimento mais qualificado para seus usuários.

Outras bibliotecas americanas pioneiras em iniciativas de utilização de novas tecnologias para os serviços de atendimento são as bibliotecas universitárias, como as das universidades de Michigan, MIT, Ohio e Yale. É possível ver iniciativas importantes também nas bibliotecas públicas que atendem usuários muito mais diversificados, com demandas totalmente diferentes das bibliotecas especializadas e universitárias, provando que a utilização dessas ferramentas tecnológicas pode ajudar a unidade de informação, no que diz respeito ao atendimento aos usuários.

Outro ponto a ser considerado é a literatura disponível sobre o assunto, que atualmente está baseada em artigos de publicações periódicas em Ciência da Informação, em sua maioria em inglês, onde se podem observar as maiores iniciativas em relação a estudos referentes à utilização da web 2.0 como aliados nas bibliotecas.

No Brasil, já existem alguns estudos relacionados à biblioteca 2.0, 0 que é e como surgiu, mas pouca informação sobre a efetiva utilização das ferramentas da web 2.0 nas nossas bibliotecas. Esse atraso se deve mais à postura dos profissionais da informação do que ao fato de o Brasil ser um país considerado em desenvolvimento. O pensamento predominante no nosso meio bibliotecário é de apatia, os profissionais ainda não vêem essas ferramentas como uma possibilidade de evolução e desenvolvimento no funcionamento das bibliotecas, principalmente nos serviços de referência. 
Para que essas iniciativas obtenham sucessos em países como o Brasil, é preciso que se quebre o paradigma dos métodos de funcionamento e atendimento já consolidados. Esse processo deve começar, ainda, da formação desses profissionais nas universidades. É preciso mostrar como essas ferramentas são o futuro e que já podem e devem ser aproveitadas no presente.

É certo que existem vantagens, mas há, também, desvantagens, e que esse processo deve ser estudado para que as bibliotecas se adequem às ferramentas que mais lhes forem pertinentes. É claro que não é necessário que todas as ferramentas sejam adotadas. É preciso verificar em quais pontos e com quais ferramentas 0 atendimento pode ser melhorado, pois iniciativas sem discussões e estudos prévios podem sufocar a biblioteca e afastar o usuário, em vez de aproximá-lo.

A segurança da informação é outro ponto que deve ser considerado ao se utilizar a web 2.0, ainda frágil nesse aspecto. Ferramentas que possam prejudicar a segurança interna da rede devem ser evitadas, devido à fácil disseminação de vírus e programas maliciosos neste meio.

A expectativa é que no futuro as bibliotecas se tornem mais virtuais do que físicas, mas que jamais deixarão de existir. Porém, essa certeza só se confirma em casos em que a biblioteca está disposta a adotar novas tecnologias na busca pelo acompanhamento da evolução informacional que está acontecendo.

As bibliotecas podem e devem utilizar a web 2.0 para oferecer produtos e serviços a seus usuários. Acompanhar a tecnologia faz parte do processo de evolução de qualquer instituição; o desenvolvimento permitido por essas ferramentas demonstra a força da biblioteca e o princípio de uma revolução na Ciência da Informação.

\section{Referências}

AGRUPAMENTO VERTICAL DE ESCOLAS DE VILA POUCA DE AGUIAR SUL (Portugal). Biblioteca. Disponível em: < http://bibliotecaspacosbrandao.blogspot.com/>. Acesso em: 14 de fev. 2012.

ALMEIDA, R. L. de. Disseminação de conteúdos na Web: a tecnologia RSS como proposta para a comunicação científica. 2008. 192 f. Dissertação (Mestrado em Ciência da Informação) - Departamento de Ciência da Informação e Documentação, Universidade de Brasília, Brasília, 2008.

AMERICA'S CAREER INFONET. CareerOneStop. Disponível em: <http://www.acinet.org/videos/COS_videos.asp? nodeid=27>. Acesso em: 14 fev. 2012.

ARNAL, D. M. Informe APEI sobre la web social. Gijón: APEI, 2008. 40 p.

BARUCH COLLEGE. William and Anita Newman Library. Disponível em: <http://newman.baruch.cuny.edu/index.php>. Acesso em: 14 fev. 2012.

BOOKS

IREAD.

Disponível

em:

<http://www.facebook.com/s.php?q=Books+iRead\&init=quick\#/apps/application.php

? id=2406120893\&ref=s >. Acesso em: 14 fev. 2012. 
BREEDING, $M$. Instant messaging: it's not just for kids anymore. Computers in Libraries, v. 23, n. 10, p. 38, Nov./Dec. 2003.

BUTLER UNIVERSITY. University Libraries. Disponível em: <http://www.butler.edu/library/>. Acesso em: 14 fev. 2012.

COLORADO COLLEGE. Tutt Library. Disponível em: <http://www.coloradocollege.edu/library/index.php/>. Acesso em: 14 fev. 2012.

CRAWFORD, W. Shiny toys or useful tools? Cites \& Insights, v. 9, n. 3, Feb. 2009. Disponível em: <http://citesandinsights.info/v9i3a.pdf>. Acesso em: 15 jul. 2009.

CUNHA, M. B. da; CAVALCANTI, C. R. de O. Dicionário de Biblioteconomia e Arquivologia. Brasília: Briquet de Lemos, 2008. 451 p.

FACEBOOK LIBRARIAN. Disponível em: $<$ http://www.facebook.com/group.php?gid=2210901334>. Acesso em: $14 \mathrm{fev}$. 2012.

FICHTER, D. Why and how to use blogs to promote your library's services. Infotoday, v. 17, n. 6, Nov./Dec. 2003. Disponível em: <http://www.infotoday.com/mls/nov03/fichter.shtml>. Acesso em: 14 jun. 2009.

FRUMKIN, J. The wiki and the digital library. OCLC Systems \& Services, v. 21 , n. 1, p. 18-22, p. 18-22, Jan. 2005.

GILMOUR, R.; STICKLAND, J. Social bookmarking for library services: bibliographic access through Delicious. College \& Research Library News, v. 70, n. 4, abr. 2009. Disponível em: $<$ http://ala.org/ala/mgrps/divs/acrl/publications/crlnews/2009/apr/socialbookmrkg.cfm $>$ Acesso em: 15 jun. 2009.

IBICT. Biblioteca Digital de Teses e Dissertações. Disponível em: <http://bdtd.ibict.br/>. Acesso em: 14 fev. 2012.

ITHACA COLLEGE. Ithaca College Library. Disponível em: <http://www.ithaca.edu/library/>. Acesso em: 14 fev. 2012.

KANSAS STATE UNIVERSITY. Library. Disponível em: <http://ksulib.typepad.com/>. Acesso em: 14 fev. 2012.

LANCASTER, F. W. Avaliação de serviços de bibliotecas. Brasília: Briquet de Lemos, 2004. 356 p.

LIBRARY OF CONGRESS. Historic Photos. Disponível em: < http://www.flickr.com/photos/library of congress/collections/72157601355524315/ >. Acesso em: 14 fev. 2012.

LIBGUIDES LIBRARIAN. Disponível em: <http://www.facebook.com/apps/application.php?id=2409492434 >. Acesso em: 14 fev. 2012.

LIBRARY OF CONGRESS. Library of Congress Channel. Disponível em: <http://www.youtube.com/user/LibraryOfCongress>. Acesso em: 14 fev. 2012. 
LIBRARY OF CONGRESS. RSS Feeds and Email Subscriptions. Disponível em: <http://www.loc.gov/rss/>. Acesso em: 14 de fev. 2012.

LIBRARY SUCESS. Disponível em: $<$ http://www.libsuccess.org/index.php?title=Online Reference $>$. Acesso em 14 fev. 2012.

MANESS, J. M. Library 2.0 theory: web 2.0 and its implications for libraries. Webology, v. 3, n. 2, jun. 2006. Disponível em: <http://webology.ir/2006/v3n2/a25.html>. Acesso em: 14 maio 2009.

MASSACHUSSETS INSTITUTE OF TECHNOLOGY. MIT Libraries. RSS Feeds by topic. Disponível em: <http://news-libraries.mit.edu/blog/rss-feeds/> Acesso em: 14 fev. 2012.

MATHIES, B.; HELMKE, J.; SLATER, P. Using a wiki to enhance library instruction. Indiana Libraries, v. 25, n. 3, p. 32-34, 2006.

O'REILLY, T. Web 2.0: compact definition. O'Reilly Radar, Oct. 1, 2005. Disponível em: <http://radar.oreilly.com/archives/2005/10/web 20 compact definition.html>

Acesso em: 4 abr. 2009.

OHIO PUBLIC LIBRARY INFORMATION NETWORK. Disponível em: <http://www.oplin.lib.oh.us/>. Acesso em: 14 fev. 2012.

SECKER, J. LASSIE: Libraries and social software in education: case study 5: libraries and facebook. London: University of London; Centre for Distance $2008 . \quad$ Disponível em: <http://clt.Ise.ac.uk/Projects/Case_Study_Five_report.pdf>. Acesso em: 9 maio 2009.

STEPHENS, M. Priceless images: getting started with Flickr. Tame the Web. 2009. Disponível em: <http://tametheweb.com/2008/01/02/priceless-images-getting-startedwith-flickr/>. Acesso em: 10 maio 2009.

UNIVERSIDADE AUTÔNOMA DE BARCELONA. Disponível em: < http://blogs.uab.cat/busempresarials/>. Acesso em: 14 fev. 2012.

UNIVERSIDADE DO AVEIRO. Serviços de Biblioteca, Informação Documental e Museologia. Blogue: A Biblioteca em forma. Disponível em: < http://blogs.ua.pt/biblioteca/>. Acesso em: 14 fev. 2012.

UNIVERSITY OF BAYLOR. Baylor University Libraries. Disponível em: $<$ http://www.baylor.edu/lib/electrres/index.php?id=37457>. Acesso em: $14 \mathrm{fev}$. 2012.

UNIVERSITY OF CALIFORNIA SAN DIEGO. Science and Engineering Library. Disponível em: <http://libraries.ucsd.edu/locations/se/>. Acesso em: 14 fev. 2012.

UNIVERSITY OF MICHIGAN. University Library. Research guides. Disponível em: <http://guides.lib.umich.edu/content.php?pid=24734>. Acesso em: 14 fev. 2012. 
UNIVERSITY OF SYDNEY. Meta Wiki. Disponível em: $<$ http://wiki.arts.usyd.edu.au/meta/index.php/Main Page $>$. Acesso em: 14 fev. 2012.

VALDOSTA STATE UNIVERSITY. Odum Library. Disponível em: $<$ http://www.valdosta.edu/library/>. Acesso em: 14 fev. 2012.

WEBB, P. L. YouTube and libraries: it could be a beautiful relationship. College \& Research Library News, v. 68, n. 6, jun. 2007. Disponível em: $<$ http://www.ala.org/ala/mgrps/divs/acrl/publications/crlnews/2007/jun/youtube.cfm> Acesso em: 10 jun. 2009.

YORK, K. Instant messaging available at library. Ohio Library News. 2009. Disponível em: < http://oplin.org/ohiolibrarynews/?p=419>. Acesso em: 30 maio 2009. 